\title{
Corf-9506192-1
}

UCRL-JC-120812

PREPRINT

\section{A MEMS-based Miniature DNA Analysis System}

\author{
M. A. Northrup \\ C. Gonzalez \\ D. Hadley \\ R. F. Hills \\ P. Landre
}

\author{
S. Lehew \\ R. Saiki \\ J. J. Sninsky \\ R. Watson \\ R. Watson, Jr.
}

This paper was prepared for submittal to

Transducers '95

Stockholm, Sweden

June 25-29, 1995

April 25, 1995

This isa preprint of a paper intended for publication in a journalor proceedings since changes may be made before publication, this preprint is made available with the understanding that it will not be cited or reproduced without the permission of the author. 


\section{DISCLAIMER}

This document was prepared as an account of work sponsored by an agency of the United States Government. Neither the United States Government nor the University of California nor any of their employees, makes any warranty, express or implied, or assumes any legal liability or responsibility for the accuracy, completeness, or usefulness of any information, apparatus, product, or process disclosed, or represents that its use would not infringe privately owned rights. Reference herein to any specific commercial product, process, or service by trade name, trademark, manufacturer, or otherwise, does not necessarily constitute or imply its endorsement, recommendation, or favoring by the United States Government or the University of California. The views and opinions of authors expressed herein do not necessarily state or reflect those of the United States Government or the University of California, and shall not be used for advertising or product endorsement purposes. 


\section{DISCLAIMER}

Portions of this document may be illegible in electronic image products. Images are produced from the best available original document. 


\title{
A MEMS-BASED MINIATURE DNA ANALYSIS SYSTEM
}

\author{
M. A. Northrup, C. Gonzalez, D. Hadley, R. F. Hills, P. Landre, S. Lehew, \\ R. Saiki ${ }^{1}$, J.J. Sninsky ${ }^{1}$, R. Watson ${ }^{1}$, and R. Watson, Jr. ${ }^{1}$ \\ Microtechnology Center, L-222, Lawrence Livermore National Laboratory \\ Livermore, CA. USA 94551 \\ ${ }^{1}$ Roche Molecular Systems, Alameda, CA. USA 94501
}

\begin{abstract}
SUMMARY
In this report we detail the design and development of a miniature thermal cycling instrument for performing the polymerase chain reaction (PCR) that uses microfabricated, silicon-based reaction chambers. The MEMSbased, battery-operated instrument shows significant improvements over commercial thermal cycling instrumentation. Several different biological systems have been amplified and verifyed with the miniature PCR instrument including the Human Immunodeficiency Virus (HIV); both cloned and genomic DNA templates of $B$ globin; and the genetic disease, Cystic Fibrosis (CF) from human DNA. The miniaturization of a PCR thermal cycler is the initial module of a fullyintegrated portable, low-power, rapid, and highly efficient bioanalytical instrument.
\end{abstract}

\section{INTRODUCTION}

The polymerase chain reaction (PCR) is an ideal bioanalytical procedure for miniaturization due to the inherent simplicity of the required instrumentation and the versatility of this in vitro DNA replication method. The PCR technique greatly simplifies the manipulation and detection of nucleic acids. Over the last decade, PCR has evolved from a procedure carried out by a small number of sophisticated molecular biologists to a simple tool in many clinical laboratories. An example of the analytical prowess of the PCR technique is reflected in the ability to simultaneously amplify multiple targets from human genomic DNA. This multiplex approach allows significantly higher levels of stringency and wider applicability of the PCR technique for complex disease or pathogen identification. One example of the value of a multiplex PCR system is detection of the genetic disease, cystic fibrosis. Cystic fibrosis (CF) is the most common severe autosomal recessive disease among Caucasian populations, with an incidence of approximately one affected individual in 2,500 newborns. The primary clinical symptoms are chronic pulmonary obstruction and infection, exocrine pancreatic dysfunction, and abnormally high levels of sweat electrolytes The frequency of asymptomatic carriers of the CF gene is estimated to be about 1 in 25 individuals.

An example of the application of micromachining to chemical analyses is the work of Manz et al (1994). In that work, the authors point out the specific advantages of miniaturizing the chromatographic and electrophoretic techniques, and achieve those advantages through the microfabrication of the separation channels. Similar advantages are gained by miniaturizing chemical reaction chambers, which is the subject of the present work.

In this report we detail the design and development of a hand-held, low-power, feedback-controlled instrument for PCR that uses microfabricated, silicon-based reaction chambers. This is an extension of previous work (Northrup et al, 1993) that demonstrated silicon-based reaction chambers. Issues that were addressed for the development of microfabricated, silicon-based reaction chambers for PCR include: thermal uniformity and temperature precision of the reaction chambers, temperature ramp rates of the chambers, and biocompatibility of the materials in contact with the reagents. 


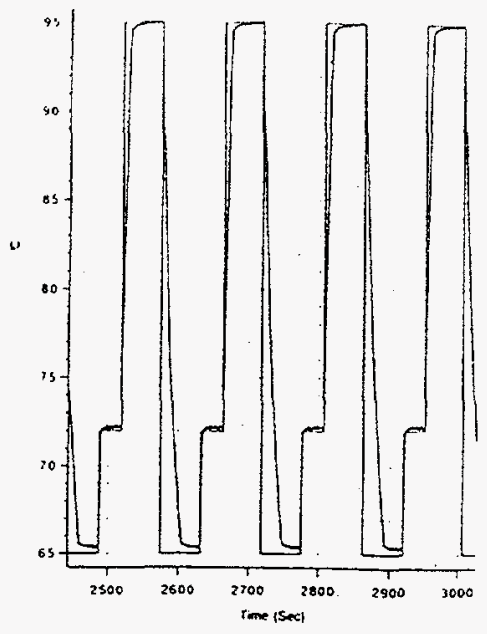

Figure 1. Example of a thermal cycle obtained with the LLNL miniature thermal cycler.

We have performed experiments that show the quantitative nature of the PCR process in both the LLNL and commercial instruments. These experiments consisted of removing $5 \mu \mathrm{L}$ aliquots out of a 105 starting copies, B-globin PCR from both the instruments at $23,25,27,29$, and 31 cycles. These aliquots were subsequently run on an agarose electrophoresis gel. The results from both instruments are virtually identical and are shown in Figure 2. The same quantitative gel electrophoresis series results from the amplification of the 268-bp target of B-globin directly from human genomic (HL60) DNA were performed.

Multiplex PCR is considered to one of the most recent and analytcally-powerful DNA amplification techniques. It requires precise and uniform temperature control within the reaction chamber. We have achieved this with the LLNL instrument.

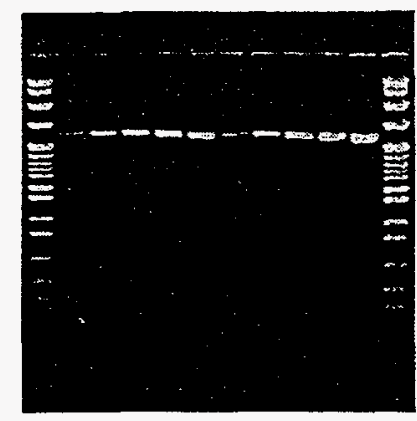

Figure 2. ETBr stained electrophoresis gel indicating the quantitative amplification series in the LLNL instrument (left series) and in a PerkinElmer GeneAmp \& 9600 Thermal Cycler. (right series).
Post PCR-detection of the specific mutations associated with the $\mathrm{CF}$ disease can be identified with simple nylon-based test strips, using reverse-dot-blot technology as illustrated in Figure 3. The test strip has specific, immobilized DNA probes containing the mutation sequence of interest. The multiplex PCR amplification products are put into a simple reagent trough along with the assay. If binding occurs and the DNA is retained after a wash step, the the DNA-biotin-streptavidinenzyme complex will turn color upon treatment with the substrate. The commercial and LLNL instrument-amplified results of PCR followed by reverse-dot-plot assay for CF are shown in Figure 4.

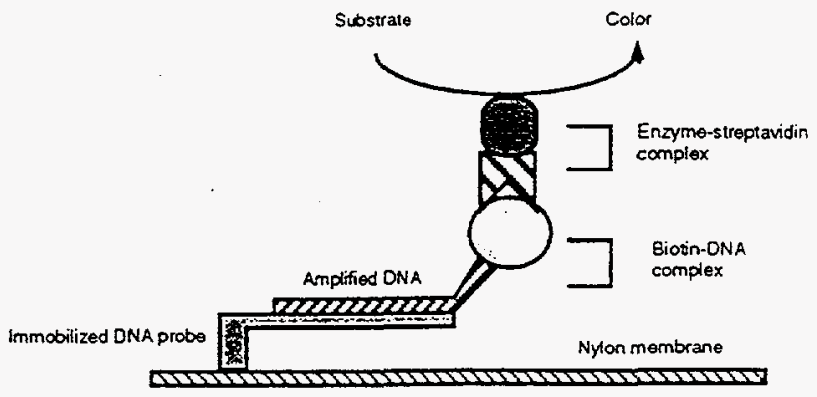

Figure 3. Schematic diagram of the human $C F$ specific, DNA-probe, reverse dot-plot assay for the detection of PCR-amplified mutations.

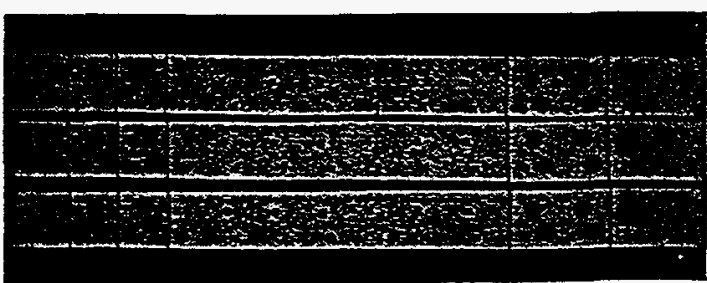

Figure 4. Photograph of $C F$-specific $P C R$ product-based, reverse doi plot detection from LLNL (rop) and commercial instruments (bottom (wo). 


\section{EXPERIMENTAL}

Reaction Chambers. Several different sizes of PCR reaction chamber designs were fabricated using integrated circuit (IC)-type silicon processing steps. The generalized fabrication process was as follows: Three-inch round, $0.5 \mathrm{~mm}$ thick single crystal silicon (SCS) wafers were processed in the following way: low stress (200$300 \mathrm{MPa}$ ) silicon nitride $\left(\mathrm{Si}_{\mathrm{x}} \mathrm{N}_{\mathrm{y}}\right.$ ) was low-pressure chemical vapor (LPCVD) deposited onto entire wafer (1.0-2.0 $\mu \mathrm{m}$ thick). Photolithographic patterns for reaction chamber and subsequent processing steps were taken in the following order: 1) the silicon nitride was reactive ion etched (RIE) over the reaction chamber area, 2) the SCS was etched to the silicon nitride backside defining the chamber volume, 3) the wafer was patterned and chemically etched away everywhere except over the nitride membrane or left over the entire surface, depending upon the reaction chamber design, 4) the remaining silicon nitride membrane (side opposite the chamber) was LPCVD deposited with polycrystalline silicon (polysilicon) to a thickness of $3000 \AA$, 5) the polysilicon was then high temperature doped with boron to a resistivity of 50-200 ohms per square, and 6) either aluminum or gold thin-film metal contacts were deposited defining the heater geometry.

Each wafer potentially contains many reaction chambers, depending upon geometry and volume desired. The etched depression in each wafer constitutes one-half of a dual-heater reaction chamber. Processed wafers are subsequently bound together forming an enclosed chamber with heaters on both sides.

The reaction chambers were bonded together by depositing a thin film of low. temperature-curing polyimide between the two wafers directly. A high precision computercontrolled silicon saw was used in each design to cut out each dual-heater chamber. The chambers were then rinsed repeatedly with de-ionized water and dried prior to treatment with silane.

Reaction Chamber Controller Instrumentation. The reaction chambers were inserted into a pressure-fit electrical contact holder that was part of the plexiglas backboard of the electronics components making up the controller. The backboard was 3 inches by 5 inches and consisted of the thermocouple-based temperature feedback control circuitry, heater electronics, computer interface, and power source connector. The circuitry was designed to work from 8 to 32 volts. Thermal calibration was accomplished by correlating the temperature of the fluid with that of the silicon-measuring Type $\mathrm{K}$ thermocouple.
Once calibrated, the instrument was capable of automated, feedback-controlled, thermal cycling operation without direct measurement of the reaction fluid. The thermal cycler output is to an Apple Centris 650 computer which displays the thermal cycle real-time along with storing the accumulated profiles. Four nine-volt batteries were able to run the entire instrument continuously for over 2.5 hours.

Reagents and PCR Parameters. PCRs were set-up as scaled-up master mixes, to assure uniformity between aliquotes thermocycled under different conditions. Reagent amounts were based on those ideal for 50 ul reactions. In general, master mixes contained: $50 \mathrm{mM} \mathrm{KCl}, 10 \mathrm{mM}$ Tris$\mathrm{HCl} \mathrm{pH} 8.3,1.5-3.0 \mathrm{mM} \mathrm{MgCl} 2,200$ uM each deoxynucleotide, or $800 \mathrm{uM}$ dNTP total, $0.5 \mathrm{uM}$ each of two oligonucleotide primers, 25 units $/ \mathrm{ml}$ AmpliTaq ${ }^{\circledR}$ DNA polymerase, and target template at a specified copy number per 50 ul reaction. Template for some of the B globin PCRs was added as single strand DNA from a M13 bacteriophage clone of a portion of the human $B$ globin gene. CF template was human genomic, double stranded, DNA derived from a cultured cell lines, HL60, GM07460, or GM08345. Each reaction mixture was aliquoted from the same master mix and thermocycled in the LLNL instrument and a Perkin-Elmer GeneAmp $\otimes 9600$ Thermal Cycler. Thermocycled reactions from both LLNL and the commercial thermal cyclers were fractionated on $3 \%$ NuSeive, $1 \%$ Seakem agarose (FMC corp.) using tris-borate buffer. The gels were stained with ethidium bromide and photographed under illumination with $302 \mathrm{~nm}$ UV light.

Although initially conceived as single use, disposable reaction chamber, the robust nature and stable properties allowed for repeated use of the reaction chambers.

\section{RESULTS}

The MEMS-based thermal cycling instrument has been tested with a variety of PCR systems, including both viral and human genomic templates. As well, various changes in both the reaction chamber design and controller instrumentation have been implemented and evaluated. A controller output real-time display of a thermal cycle from microfabricated thermal cycler is shown in Figure 1. It can be seen that with 15 volts input (average $1.2 \mathrm{~W}$ atts) that heating rates of over $5{ }^{\circ} \mathrm{C} / \mathrm{sec}$ are attained. Cooling is slightly slower $\left(2.5^{\circ} \mathrm{C} / \mathrm{sec}\right)$. mostly due to the fact that the reaction chamber is held inside a plexiglas instrument board. Precision of $+1-0.5^{\circ} \mathrm{C}$ is maintained at the target temperatures. 


\section{DISCUSSION}

From these results and previous ones with singlesided heaters (Northrup et al 1993), it appears that silicon-based reaction chambers of various sizes and configurations are capable of carrying out PCR with low power requirements. Wittwer et al (1990) and recent work (1995) has shown high heating and cooling rates with a high-power, tabletop instrument using glass capillary tubes. Those studies indicated that short cycle times benefit the fidelity and specificity of the PCR process.

PCR also been shown to work in simple, etched-silicon cavities with an anodically-bonded glass top. Those silicon test tubes were cycled in a table-top pelletier instrument (Wilding et al, 1994). Due to slow cycle times ( -3 min per cycle) large amounts of non-specific amplification product was formed in those results.

The rapid temperature cycling and thermal and uniformity now possible in a PCR compatible reaction chamber may provide insight into hybridization and enzyme kinetics. For example, the importance of temperature control is paramount in the $P C R$ process, especially when complex systems are to be amplified (e.g. human genomic DNA, multiplex amplifications). Precise temperature control as well as thermal uniformity must be balanced. To truly miniaturize the instrument or take advantage of microfabricated reaction chambers in order to a build highthroughput instrumentation, one must integrate the control elements on a unit-by-unit scale. Thermal properties of the various materials used must also be balanced to combine efficient control with thermal lability. Silicon-based materials afford the requisite thermal properties, the ability to integrate heaters and feedback control, and their manufacture takes advantage of highly parallel, automated, and batched processing.

The significance of the results presented here is that for the first time, battery-operated, hand-held, PCR amplification; and simple reagentbased, targeted detection of complex biologicals and diseases are possible.

\section{REFERENCES}

Manz, A., Verpoorte, E., Raymond, D.E., Effenhauser, C.S., Burggraf, N., and Widmer, H.M., $\mu T A S:$ Miniaturized Total Chemical Analysis , in Micro Total Analysis Systems, A. van den Berg and $P$. Bergveld (eds.). Kluwer Academic Publishers, Dordrecht, NL, 1995. 5-29.

Northrup, M.A., Ching, M.T.. White. R.M., and Watson, R.T., DNA Amplification in a Microfabricated Reaction Chamber. In
Transducers ' 93. Seventh International Conference on Solid State Sensors and Actuators, Yokohama, Japan, June 7-10, 1993, 924-926.

Wilding, P., Shoffner, M.A., and Kricka, L.J., $P C R$ in a Silicon Microstructure, Clin. Chem. 40(9), 1994, 1815-1818.

Wittwer, C.T., Fillmore, G.C., and Garling, D.J., Minimizing the time required for DNA amplification by efficient heat transfer to small samples, Analytical Biochemistry 186, 1990, 328331 .

Wittwer, C.T, Personal Communication, 1995.

\section{ACKNOWLEDGEMENTS}

Work performed under the auspices of the U.S. Department of Energy by Lawrence Livermore National Laboratory, contract number W-7405ENG-48. The authors acknowledge the support of the MEMS program of the Advanced Research Projects Agency. We would also like to acknowledge the collaboration and support of Roche Molecular Systems of Alameda, Ca.

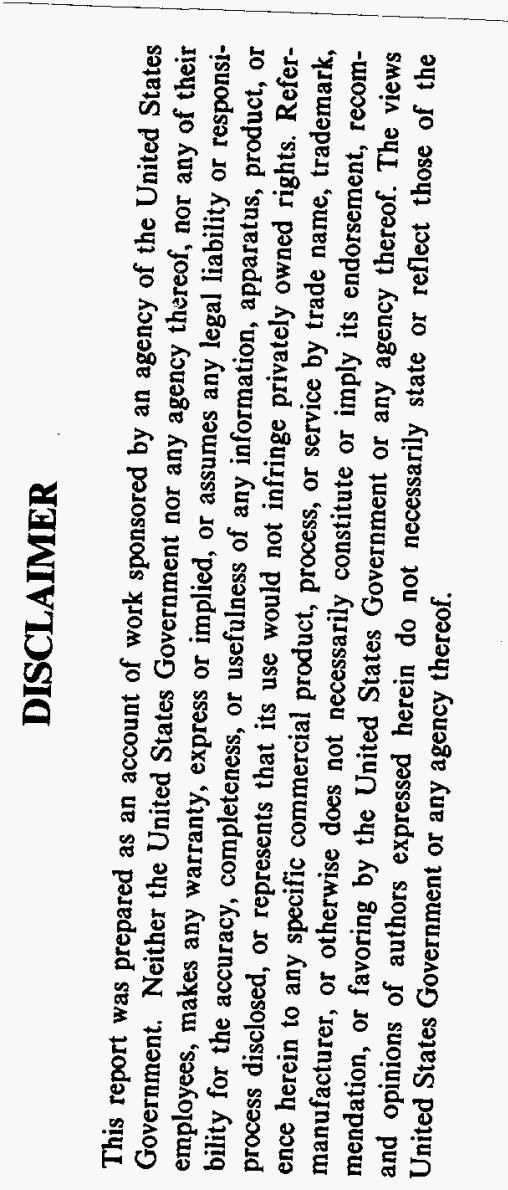

